\title{
Construction of Multifunctional Video Conversion-based Multimedia Teaching System for College Basketball
}

\author{
https://doi.org/10.3991/ijet.v13i06.8587 \\ Feng Sheng, Shaozeng Sheng \\ Qufu Normal University, Qufu, China \\ 3352165615 @qq.com
}

\begin{abstract}
Animation demonstration is an important manifestation of multimedia technology. In the past, low flexibility and long research and development cycle are typical problems of animation demonstration system and video conversion technology. Through introducing an advanced teaching method (understanding approach) and multimedia technology (video conversion system based on SOPC) for theoretical construction, this study designed a video conversion system based on SOPC, finally constructed a multifunctional video conversion-based multimedia teaching system from the aspect of module design and functional design, and used a randomized controlled experiment to test students' learning outcomes in the course of college basketball. The results show that students' offensive understanding ability and defensive understanding ability improved greatly after the system was used in teaching. It plays an important role in improving the usability and effectiveness of multimedia teaching system.
\end{abstract}

Keywords-Video conversion software; animation demonstration teaching mode; FLASH; College Basketball

\section{Introduction}

With the rapid development of internet and network technology, animation demonstration has gradually become a technology with urgent demand and broad market prospect in recent years. Animation demonstration mode emerged with the appearance of network media environment and has gained the rapid development. Animation demonstration is characterized by interesting contents and rich pictures. It cannot just motivate students' learning interest, but also enrich their creativity [1]. Through vivid animation demonstration, some theories which are difficult to deeply explain in traditional teaching can be demonstrated effectively so that students can grasp them better. Meanwhile, animation demonstration offers convenience for teacher's teaching. For example, many basketball teachers and coaches adopt Flash animation or other software to produce basketball animation so as to enhance technique and tactics of basketball fans.

As animation demonstration teaching mode becomes mature continuously, people's requirements for video conversion system technology becomes higher and higher. The previous video conversion system technology generally has the problems of 
low flexibility and long development period, which seriously restricts the application of animation demonstration in teaching practice. The emergency of SOPC-based video conversion system offers a flexible embedded solution to the techniques based on ARM, DSP and FPGA, and it has the features of flexible design, splicing, upgrade and reuse [2]. Meanwhile, the design and research of SOPC-based video conversion system can play a great role in transiting analog interface to digital interface and inject the new vigor for the development of video conversion technology.

At present, animation demonstration teaching mode has played an important role in the major teaching with high requirements for space such as civil engineering [3], fashion design [4] and sports. Students may understand new knowledge and new skills through watching animation demonstration. Animation demonstration teaching mode can effectively solve a series of problems in traditional teaching, then greatly reduce teaching cost and provide visualized and spatialized learning environment for learners.

\section{State of the art}

The discussion on the application of multimedia technology in PE courses such as college basketball has existed for a long time, and the researches are also rich. Zhigang et al. [5] deeply discussed necessity and feasibility of multimedia technology application in college basketball teaching, and proposed the introduction of multimedia technology could greatly enhance basketball teaching efficiency and prominently promote students' basketball knowledge and skills. The scholar also put forward the specific ways to combine multimedia technology and basketball teaching and offered the good reference for this paper. Yuan et al. [6] analyzed the feasibility of comprehension teaching method application in basketball teaching and considered such teaching method is an important way to cultivate professional talents. It contributes to improving teaching efficiency and can make students grasp basketball skills easily. Thus, it will be welcomed by teachers and students in the future. Animation demonstration teaching mode is one of hot topics researched by domestic and overseas scholars. Choi et al. [7] designed SOPC-based video conversion system, and flexibly reused IP nuclear resource to shorten the development cycle. Meanwhile, they gave full play to Micro Blaze property and simplified hardware circuit so that the design task concentrated on system function and algorithm implementation. Their research is of great significance for the development of video conversion technology. Robinson et al. [8] applied animation technology in Australian PE teaching and considered that Global Positioning System (GPS) allows coaches and sports scientists to track metrics across team and individual sports. With RunKeeper available on iPhones and Android devices, users can track speed, distance, and time during outdoor activities. The video analysis is also applied for improvement of athlete performance. Matthew et al. [9] applied video games in basketball teaching in order to confirm the relationship among basketball knowledge, skills and video games. The research result shows that the video game may be a beneficial learning tool for teachers or students. Liu [10] proposed Kinect-based 3D role model rebuilding scheme and utilized this method to 
accurately re-establish $3 \mathrm{D}$ role model in real time. Finally, motion capture data were used to drive $3 \mathrm{D}$ role model to generate $3 \mathrm{D}$ animation. The practice indicates that Kinect-based 3D role model rebuilding precision is high, with good visualization effect and high application value. In general, the previous animation demonstration teaching mode and video conversion technology have many problems. Multimedia video conversion software designed with SOPC-based video conversion system will be the development trend of multimedia teaching, and has great significance for improving system usability and enhancing students' learning interest and creativity.

Based on the development of animation demonstration teaching mode and video conversion technology, multifunctional video conversion software design is conducted in this paper. The defects of previous video conversion software are solved through introducing SOPC-based video conversion system. The innovative points of multifunctional video conversion software designed in this paper include the following: on the one hand, the application of animation demonstration teaching mode in basketball teaching can change the insufficient deepness and high understanding difficulty in traditional teaching, and construct the thorough knowledge frame for students. It greatly enhances basketball teaching efficiency. On the other hand, to expand the application scope of animation demonstration, multimedia video conversion software (Format Factory) is applied in this paper. SOPC-based video conversion system is implanted in the software to achieve video signal decoding, video format conversion, video access and output, etc. It is of great significance for teaching practice.

\section{Theoretical construction for multifunctional video conversion software}

For college multimedia courses and especially PE courses such as basketball, to change the problems of low teaching efficiency and insufficient learning interest, advanced teaching methods and multimedia technologies should be introduced. Comprehension teaching method is a teaching method which combines teaching and practice, and it is praised by many PE scholars. SOPC video conversion system is also widely approved. Thus, theory construction for multifunctional video conversion software is conducted from the following two aspects.

\subsection{Introduction of comprehension teaching method}

Different from traditional teaching method, comprehension teaching method pays attention to students' comprehension in the learning process[5]. In basketball teaching, comprehension teaching method mainly makes students grasp basic knowledge and skills through their experience of ball sport laws. For example, with comprehension teaching method, students can cognize the essence of ball sport through competitions and continuously improve competition level.

The teaching process of comprehension teaching method is as follows. Firstly, the teacher will let students view contests or videos, and explain action skills and competition rules in the meantime so as to lay a foundation for the follow-up teaching. Then, 
the teacher asks students to participate in ball sports to enhance their understanding of small-scale competitions. Finally, students' understanding of basketball sport rules is enhanced through formal competitions to improve students' basketball level and finally form lifelong exercise awareness. The comparison between comprehension teaching method and traditional teaching method is shown as table 1.

Table 1. Comparison between comprehension teaching method and traditional teaching method

\begin{tabular}{|c|c|c|}
\hline Item & Comprehension teaching method & Traditional teaching method \\
\hline Classroom subject & Student & Teacher \\
\hline Key teaching point & Tactical consciousness & Skills \\
\hline Training objective & Learning ability & Creative ability \\
\hline Learning motivation & Active absorption & Passives listening \\
\hline
\end{tabular}

\subsection{SOPC technology development}

SOPC technology is the embedded technology of software and hardware collaboration technology, including digital information processing, high speed data reception and transmission, and complex calculation, etc. The emergency of SOPC embedded system can reduce FPGA design difficulty, and greatly shorten development period. SOPC technology has the features of flexible design, splicing, upgrade and reuse, and the system based on SOPC has significant advantages in terms of scale, performance and cost. The development of SOPC technology cannot be separated from flexible IP kernel. It is the rich and sound IP kernel that drives the development of SOPC technology. IP kernels can be classified into three types. (see table 2)

Table 2. Classification of IP kernel

\begin{tabular}{|c|l|l|}
\hline \multicolumn{1}{|c|}{ Type } & \multicolumn{1}{|c|}{ Description } & \multicolumn{1}{|c|}{ Feature } \\
\hline Soft kernel & $\begin{array}{l}\text { Verilog or vhdl language is used to describe circuit } \\
\text { function, and the design is at the register level or gate } \\
\text { level. }\end{array}$ & $\begin{array}{l}\text { Short design period, high flexibil- } \\
\text { ity, expandability, low cost }\end{array}$ \\
\hline Hard kernel & $\begin{array}{l}\text { T is described with the graph. Users can only use it, but } \\
\text { cannot change it. }\end{array}$ & $\begin{array}{l}\text { Long development period, high } \\
\text { cost and low flexibility }\end{array}$ \\
\hline Fixed kernel & Compromise of soft kernel and hard kernel & Revisable, optimizable \\
\hline
\end{tabular}

It is known from the table that, rich IP kernel resources make SOPC-based system own the advantages of small structure, tailoring, IP and resource reuse, and can effectively reduce repeated work in the design.

The development of SOPC technology includes three links: soft or hardware collaborative development process, embedded processor model selection and control bus. In this paper, soft or hardware collaborative development process is mainly introduced.

In SOPC design process, real soft and hardware collaborative design makes FPGAbased embedded design convert to $\mathrm{C}$ language function description form hardware 
logic design. According to SOPC design process provided by Xilinx, hardware development focuses on SOPC system platform creation, and embedded processor type, bus type and peripheral can be chosen according to actual design demands. Hardware design of customized IP includes hardware description language design, synthesis, simulation and implementation. Software development refers to system application program design and API function writing to achieve function calling. Software process includes $\mathrm{C}$ language code writing, compiling and linking process.

\subsection{SOPC-based video conversion system design}

By referring to ASIC, DSP and FPGA, it is known that main functions of video conversion system include video decoding, processing and display. SOPC-based video conversion system improves its processing property through embedding MICROBLAZE in FPGA. When the system decodes different video data, conversion and access of video signals of different format are conducted correspondingly to achieve real-time video transmission and conversion among different interfaces. Thus, SOPC-based video conversion system includes four parts: video signal decoding, video signal processing, local output and display as well as expansion property. Correspondingly, SOPC-based video conversion system includes four parts: video signal decoding, video format conversion, video buffer, output and display. The system design scheme is as fig. 1 :

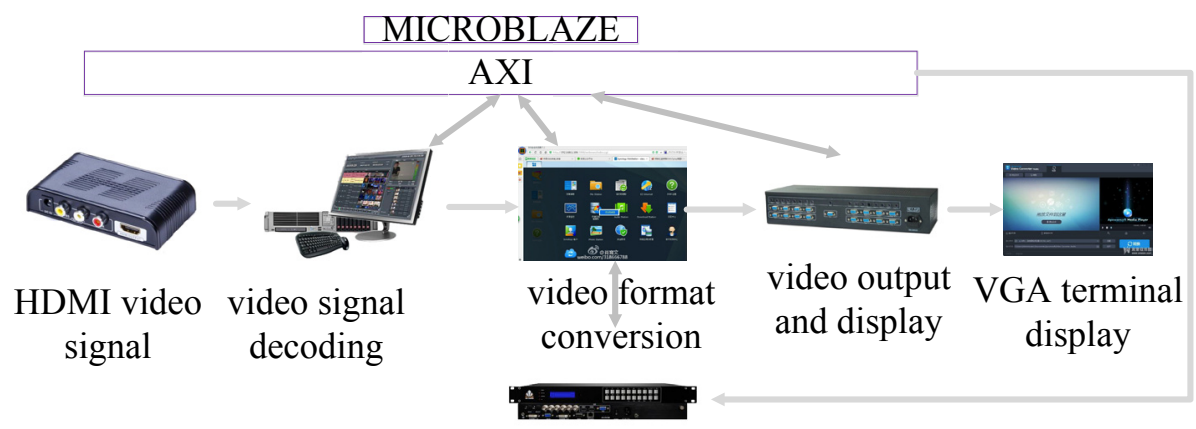

video access

Fig. 1. Design scheme of SOPC-based video conversion system

The four parts of the system are effectively combined by SOPC platform, and video conversion speed is accelerated by parallel processing of FPGA so that it owns high real-time property. The design of video format conversion link is mainly introduced in this paper.

Video format conversion converts video signal into another format from one format. In essence, it is a matter of video sampling rate conversion. Video sampling rate conversion can be achieved through three steps. Firstly, equivalent sampling dot matrixes of input and output signals as well as corresponding middle dot matrix must be confirmed. Secondly, filter frequency response is determined based on the three dot 
matrixes. Finally, a filter approximating the required response is designed. The detailed design is as follows:

Non-interlaced and interlaced scanning: raster scanning mechanism includes non-interlaced and interlaced scanning. The diagram is as fig. 2 :

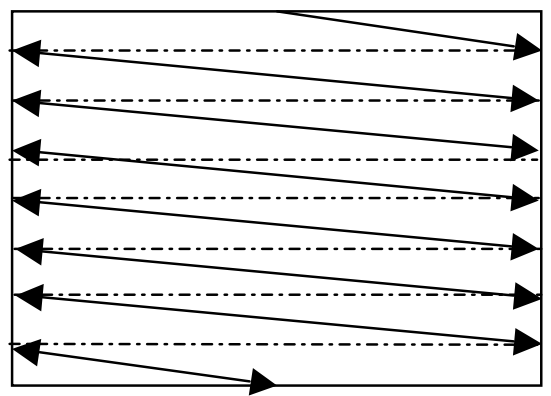

Progressive frame

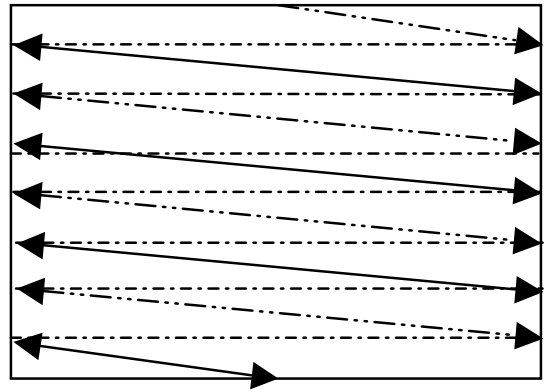

Interlaced frames

Fig. 2. Non-interlaced and interlaced scanning of SOPC-based video conversion system

In non-interlaced scanning process, electron beam or light beam scans according to the continuous motion track from the top to bottom and then to top again so as to gain conventional frame signal separated by inter-frame space $\Delta \mathrm{t}$. The gained frame signal consists of horizontal scanning lines formed by conventional vertical segmentation. Finally, image signals synthesized by a series of frames can be gained.

Interlaced scanning is based on the way that each frame is divided into two fields. Frame frequency is the half of field frequency. In interlaced scanning, the interval time between two fields is the field interval, and the time is a half of frame interval. The scanning line of two successive fields translates half line space of each field.

Video sampling: video signal actually includes 3D signals at three directions: horizontal, vertical and time. In the design process, horizontal direction is often ignored to simplify the research. $\triangle \mathrm{t}$ refers to field interval, and $\triangle \mathrm{y}$ refers to line interval. Sampling dot matrices of non-interlaced and interlaced scanning are as fig. 3 and fig. 4 : 


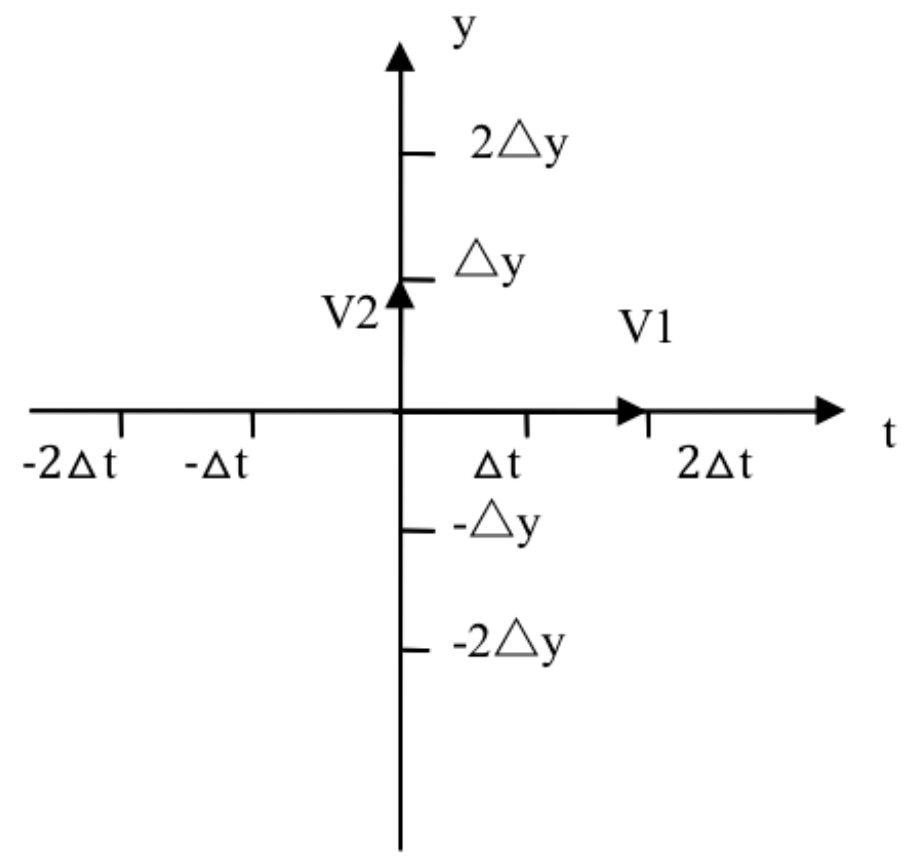

Fig. 3. Dot matrix of non-interlaced video sampling

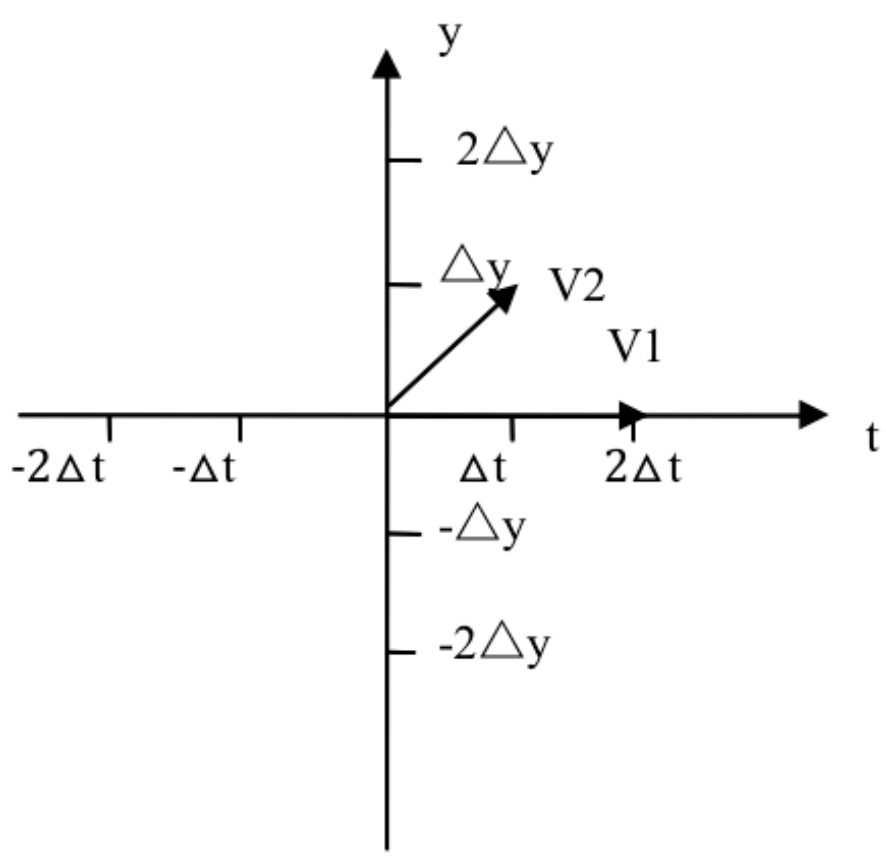

Fig. 4. Dot matrix of interlaced video sampling 
The following matrix can be generated according to the base vector shown in the figures:

$$
\begin{aligned}
& \text { Non-interlaced scanning: }\left[V_{1}\right]=\left[\begin{array}{cc}
2 \Delta t & 0 \\
0 & \Delta y
\end{array}\right],\left[U_{2}\right]=\left[\begin{array}{cc}
\frac{1}{2 \Delta t} & 0 \\
0 & \frac{1}{\Delta y}
\end{array}\right] \\
& \text { Interlaced scanning: }\left[V_{2}\right]=\left[\begin{array}{cc}
2 \Delta t & 0 \\
0 & \Delta y
\end{array}\right],\left[U_{2}\right]=\left[\begin{array}{cc}
\frac{1}{2 \Delta t} & 0 \\
\frac{-1}{2 \Delta t} & \frac{1}{\Delta y}
\end{array}\right]
\end{aligned}
$$

Video sampling rate conversion: deinterlacing conversion is to fill in the skipped lines in each field so as to gain the ideal interpolation filter.

$$
H\left(f_{y}, f_{t}\right)=\left\{\begin{array}{c}
\frac{d\left(\wedge_{2}\right)}{d\left(\wedge_{1}\right)}=2,\left(f_{y}, f_{t}\right) \in v_{1}^{*} \\
0,\left(f_{y}, f_{t}\right) \in \frac{v_{2}^{*}}{v_{1}^{*}}
\end{array}\right.
$$

\section{Development of "Format Factory" conversion software in College Basketball multimedia course}

\subsection{Development of "Format Factory" conversion software in College Basketball multimedia course}

Module design. According to the classification of core subjects, multifunctional video conversion software designed in this paper is composed of three modules: HDMI signal decoding module, video access and format conversion module, video output and display module. To be specific, HDMI signal decoding module includes HDMI receiver, IIC bus control and signal input IP, where IIC bus control part and signal input IP are on SOPC platform. Video access and format conversion module is the core of multifunctional video conversion software, including AXI-MPMC controller, AXI-Scaler IP, and AXI-VDMA IP kernel. Video output and display module includes video output IP and VGA hardware interface, where video output IP is implemented by SOPC platform. The interface of multimedia video software (i.e. "Format Factory") is shown in Fig.5.

Fig. 6 shows the operating interface screenshot of $\mathrm{CD}$ audio track converted to MP3, WMA, OGG and AAC in SOPC-based "Format Factory" conversion system. 
Paper-Construction of Multifunctional Video Conversion-based Multimedia Teaching ...

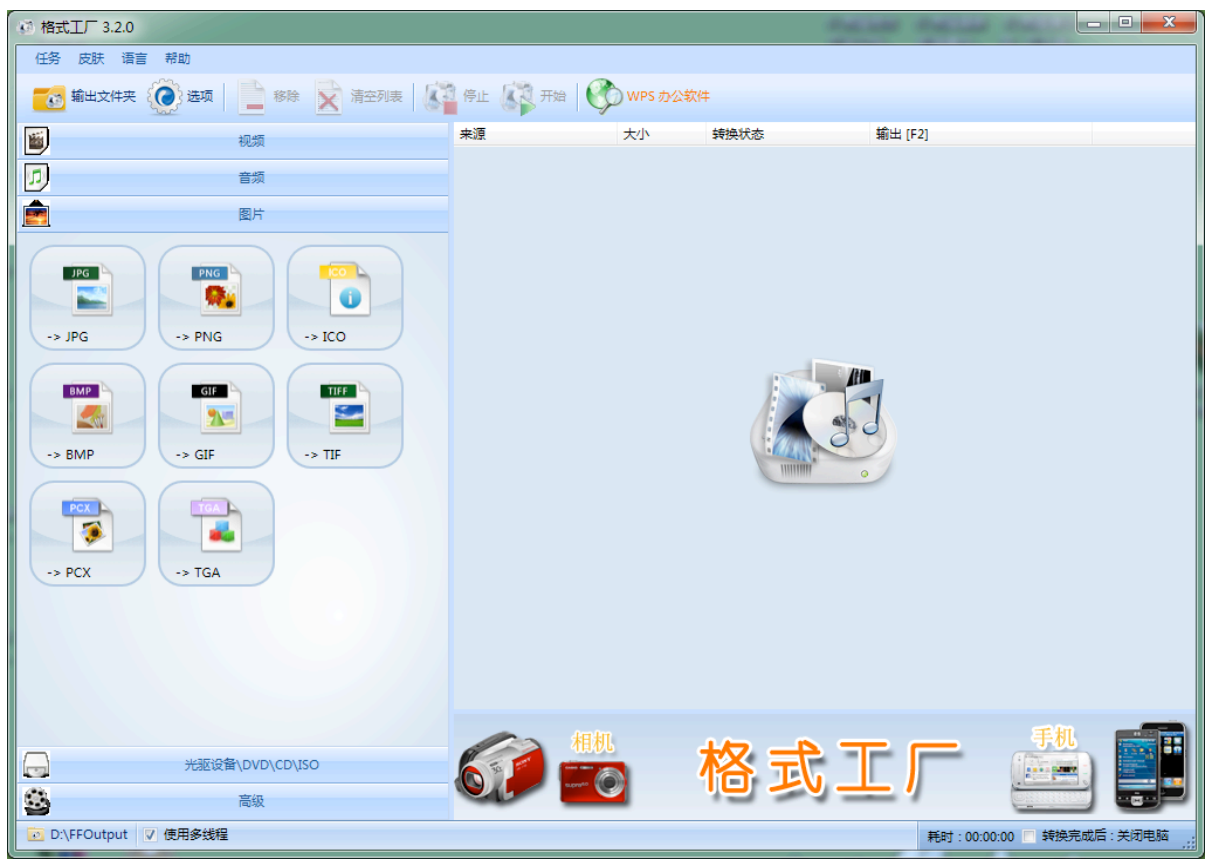

Fig. 5. Main interface of SOPC-based "Format Factory" conversion system

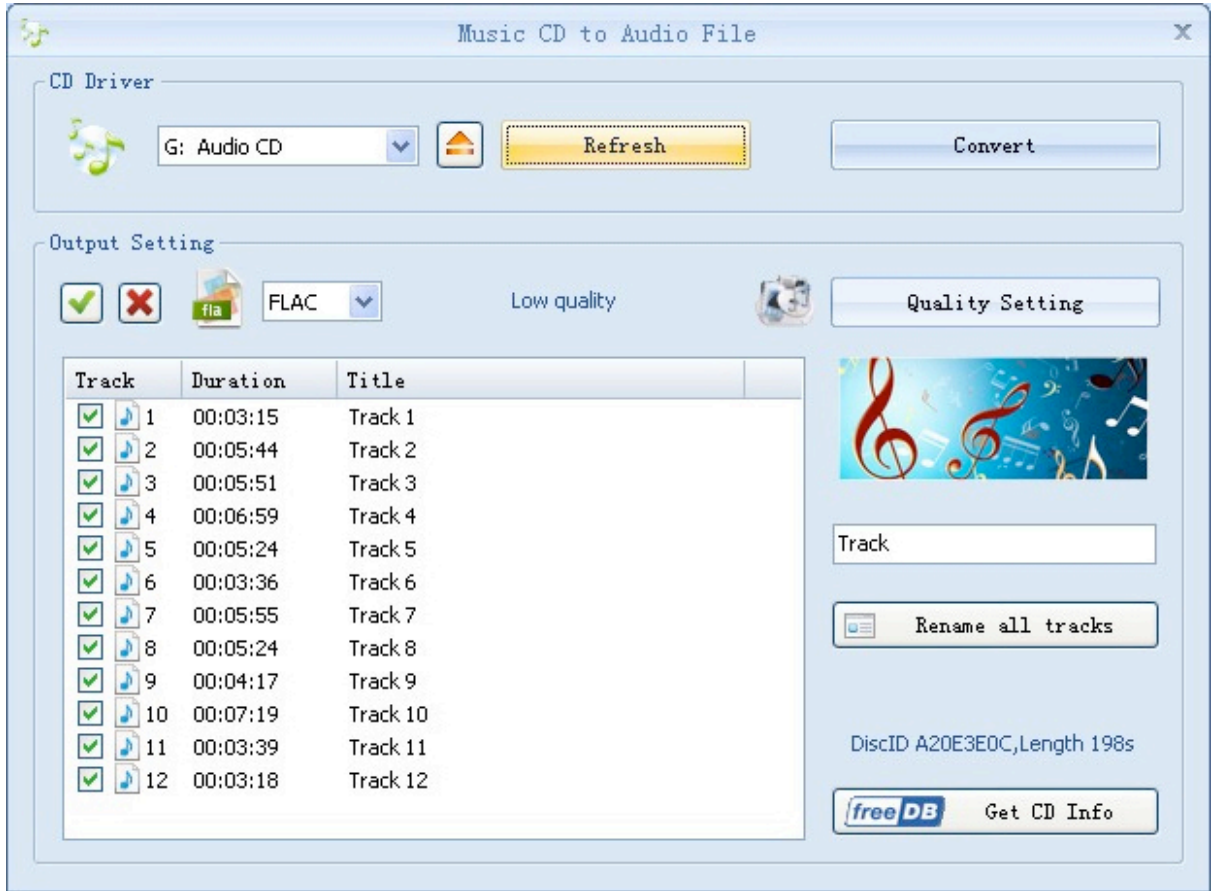

Fig. 6. Operating interface I of SOPC-based "Format Factory" conversion system 


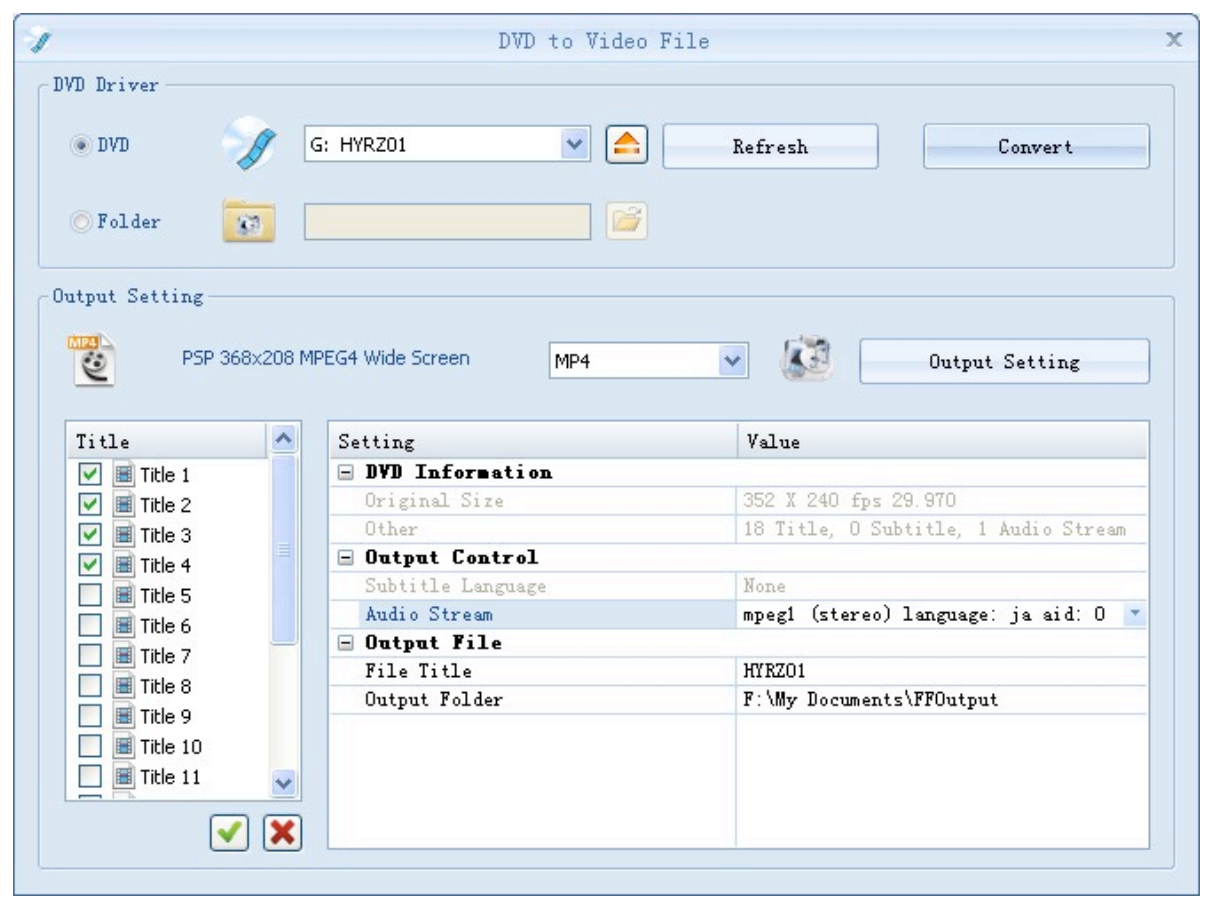

Fig. 7. Operating interface II of SOPC-based "Format Factory" conversion system

Fig.7 shows the operating interface screenshot of DVD converted to MP4, AVI, 3GP and WMV in SOPC-based "Format Factory" conversion system.

Function design. Multifunction video conversion software designed in this paper needs to implement the following functions. Firstly, it needs to implement HDM signal decoding control. The solution is that HDMI receiver control is implemented by IIC bus and then HDMI video signal is decoded. Secondly, DDR3 access is implemented by designing AXI-MPMC controller, and then video data access is achieved. Thirdly, video format conversion is implemented by AXI-Scaler controller. Fourthly, video signal is outputted after the conversion. Fig. 8 shows function design process of SOPC-based "Format Factory" conversion system.

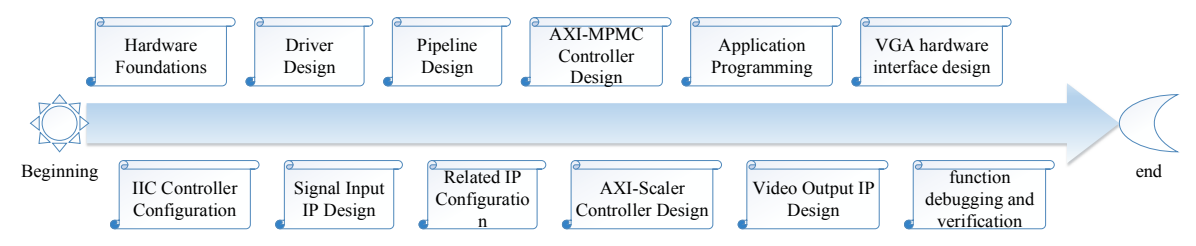

Fig. 8. Function design process of SOPC-based "Format Factory" conversion system

It is known from the figure that, function design process can be roughly divided into five links: 
- Use XPS to set up hardware platform and use BSB guide of XPS to create the foundation platform for embedded design engineering. BSB cannot just save processing time, but also meet more customization needs. BSB can automatically generate the common hardware and software platform for design of most processors. The relevant peripherals include IIC controller and UART, etc.

- Import hardware design in SDK on XPS main interface, and then use SDK to design driver program for HDMI decoding control; then input IP.

- Add and configure relevant IP according to module pipeline control thought and bandwidth requirement; design AXI-MPMC controller and AXI-Scaler controller, and implement pipeline-type video access and format conversion.

- Formulate video output IP and VGA hardware interface circuit so as to meet VGA output requirements for different video resolution ratio.

- Test and verify function module; conduct system function test, modification and verification after each module is effectively linked in one video conversion process so as to implement the expected result.

\subsection{Effect check}

Based on completing multifunctional video conversion software design, College Basketball was chosen in this paper to analyze the application of multimedia video conversion software. College Basketball is a common PE course in colleges, including basic theories and special skills. Theory teaching focuses on the development history and tactics of basketball sport. Special skills are composed of motion, passing and catching, shooting, ball handling, breaking and defending, etc. Through basketball teaching, students could set the feasible training plan according to their ability, improve basketball ability, cultivate good sportsmanship and teamwork spirit and develop the good training habit and sport culture quality.

One male class of a college was chosen, and 50 students participating in the experiment had no obvious differences in physical quality, basketball foundation and learning ability. The actual curriculum time of College Basketball is one school year. In the period from September 2017 to December 2017, comprehension teaching method and "Format Factory" conversion software were applied. In the period from March 2017 to July 2017, traditional teaching method was used. The experiment conclusion was drawn through comparing learning effect in the two semesters. After the course ended, 5 basketball teachers were invited to evaluate students' skill application and tactics comprehension. After removing one highest score and one lowest score, the average score of three students was chosen as the evaluation criterion.

Attack comprehension scoring shows that, except quick attack and three threats which require high cooperation ability, experimental group and control group have significant differences in sense of space and fixed cooperation, and show highly significant differences in free attack, motion without the ball and timing choice. Defense comprehension scoring of experimental group and control group: 
Table 3. Attack comprehension scoring

\begin{tabular}{|l|c|c|c|c|}
\hline & Experimental group & Control group & T & P \\
\hline Quick attack skill & $3.04 \pm 0.55$ & $3.41 \pm 0.25$ & 1.45 & $>0.05$ \\
\hline Three threats & $3.66 \pm 0.42$ & $3.47 \pm 0.57$ & -0.55 & $>0.05$ \\
\hline Sense of space & $2.50 \pm 0.50$ & $2.06 \pm 0.49$ & 4.60 & $<0.05$ \\
\hline Fixed cooperation & $3.21 \pm 0.52$ & $2.49 \pm 0.62$ & 4.81 & $<0.05$ \\
\hline Free attack & $3.26 \pm 0.61$ & $2.79 \pm 0.73$ & 6.13 & $<0.01$ \\
\hline Motion without the ball & $3.77 \pm 0.68$ & $2.45 \pm 1.10$ & 5.76 & $<0.01$ \\
\hline Timing choice & $3.52 \pm 0.77$ & $2.89 \pm 0.25$ & 4.93 & $<0.01$ \\
\hline
\end{tabular}

Table 4. Defense comprehension scoring

\begin{tabular}{|l|c|c|c|c|}
\hline & Experimental group & Control group & T & P \\
\hline Defense motion & $3.59 \pm 0.41$ & $3.47 \pm 0.57$ & -0.55 & $>0.05$ \\
\hline Defense path & $2.53 \pm 0.48$ & $2.06 \pm 0.49$ & 4.60 & $<0.05$ \\
\hline Defense momentum & $3.26 \pm 0.58$ & $2.49 \pm 0.62$ & 4.81 & $<0.05$ \\
\hline Defense position choice & $3.19 \pm 0.65$ & $2.79 \pm 0.73$ & 6.13 & $<0.01$ \\
\hline Defense flexibility & $3.68 \pm 0.78$ & $2.51 \pm 1.00$ & 5.76 & $<0.01$ \\
\hline Collaborative defense & $3.56 \pm 0.67$ & $2.76 \pm 0.65$ & 5.43 & $<0.01$ \\
\hline Defense reading ability & $3.57 \pm 0.74$ & $2.72 \pm 0.35$ & 4.93 & $<0.01$ \\
\hline
\end{tabular}

Seeing from defense comprehension scoring, experimental group and control group have significant differences in defense path and defense momentum, and highly significant differences in defense position choice, defense flexibility, collaborative defense and defense reading ability. Both groups have no significant difference in defense motion with high requirements for physical quality.

On the whole, the experimental group is significantly superior to the control group in terns of attack and defense, indicating "Format Factory" conversion software has the significant advantages in improving students' basketball skill level and tactics comprehension. Through the video conversion software, the students in the experimental group not just had a deeper understanding of basketball rules, but also experienced the sense of space for basketball court more vividly. The application of comprehension teaching method and "Format Factory" conversion software could help students establish correct movement presentation in advance before the practice, simulate rational motion path and tactics path, and effectively solve the difficulty in teaching movements and expressing in words in tactics teaching. Basketball teaching scene with comprehension teaching method is shown in Fig.9. 


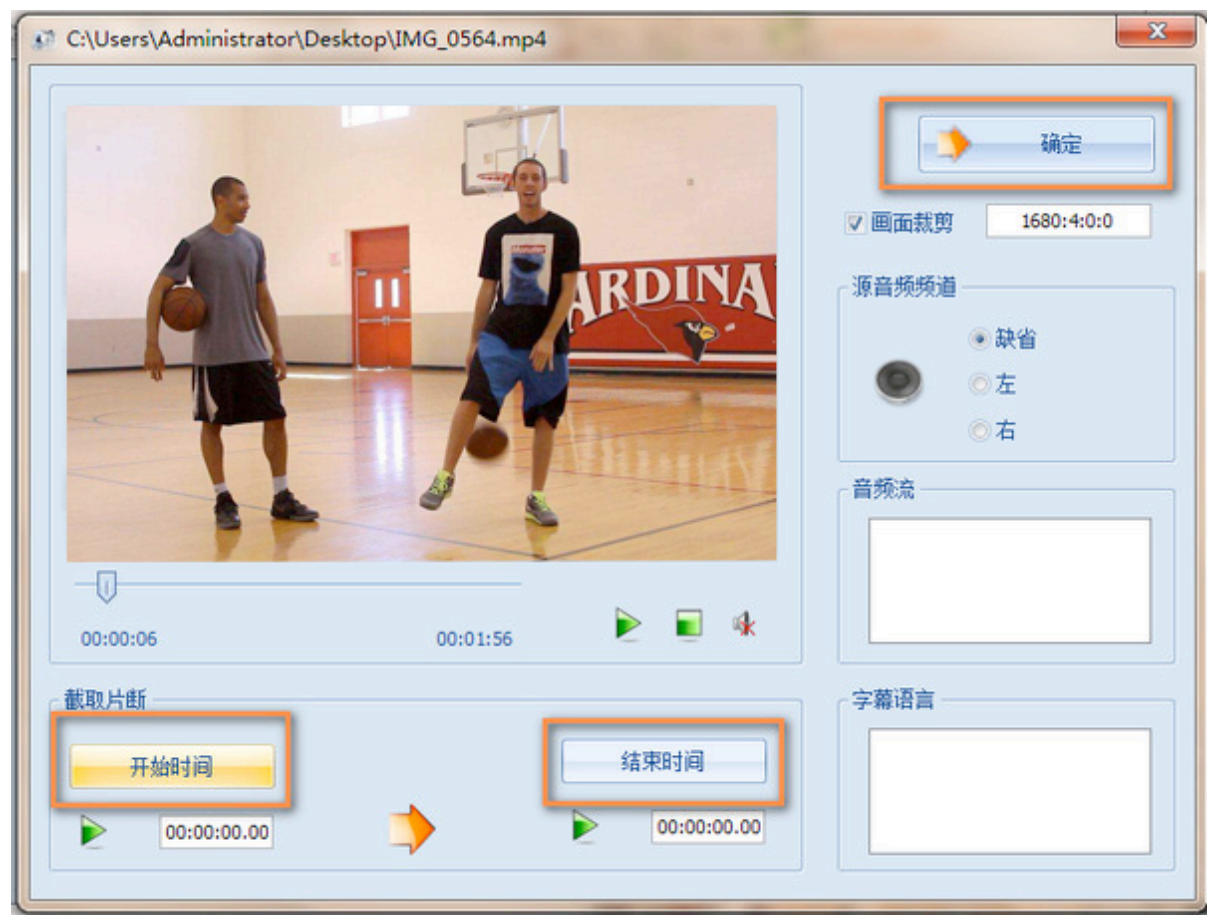

Fig. 9. Basketball teaching scene with comprehension teaching method

\section{Conclusions}

The practice proves that, the introduction of comprehension teaching method and "Format Factory" conversion software in basketball teaching is very necessary. They can offer new thoughts for basketball skill and tactics teaching and has certain promotion value and practical significance. Compared with previous teaching mode, through comprehension teaching method, teachers will choose features of ball games and tactical consciousness as teaching breakthrough and design diversified teaching competitions to motivate students' interest and then give play to their subjective initiative. "Format Factory" conversion software can provide large quantities of superior resources for teaching. It further highlights the effect of animation demonstration in teaching and offers more help for students' employment and further study.

\section{Acknowledgment}

This work was supported by Youth Fund of Humanities and Social Sciences Research Project of Education Ministry (14YJC890022) and Social Science Planning Research Project of Shandong Province (13CTYJ04). 


\section{$7 \quad$ References}

[1] Qin, Z.Y., \& Tao, Z.H. A Low Memory 3D Animation Technology for Animation Design Course. International Journal of Emerging Technologies in Learning, 2016, vol. 11(5), pp. 68-73. https://doi.org/10.3991/ijet.v11i05.5697

[2] Yi, F.R., Qian, H., Lin, P.J., \& Lai, Y.F. Implementation and design of vga controller for video conversion system. Video Engineering, 2013, vol. 37(23), pp. 69-72.

[3] Qian, B. Construction of teaching system of open experiment for engineering based on applied ability training. Experimental Technology \& Management, 2010, vol. 27(7), pp. 136138.

[4] Zhang, J. The study on virtual human costume design and animation synthesis based on three-dimensional solid model. Advances in Information Sciences \& Service Sciences, 2013, vol. 5(5), pp. 440-447. https://doi.org/10.4156/aiss.vol5.issue5.51

[5] Li, Z.G., \& Kang, J.H. Application of multimedia technology to basketball teaching. Hubei Sports Science. 2010, vol. 29(5), pp. 555-557.

[6] Yuan, H.J. Experimental study on the cooperation and competition teaching mode in basketball course in ordinary colleges and universities. Contemporary Sports Technology, 2015, vol. 5(36), pp. 37-38.

[7] Choi, K., Luo, Y., \& Hwang, J.N. Hidden markov model inversion for audio-to-visual conversion in an mpeg-4 facial animation system. Journal of Vlsi Signal Processing Systems for Signal Image \& Video Technology, 2010, vol. 29(1-2), pp. 51-61.

[8] Robinson, J. Use technology like an elite sportsperson in your classroom. Achper Active \& Healthy Magazine, 2012, vol. 19(2), pp. 11.

[9] Matthew T. Buns, \& Katherine T. Thomas. Convergent validity between a sport video game and real sport performance. Sports Technology, 2011, vol. 4(1-2), pp. 77-87. https://doi.org/10.1080/19346182.2012.691509

[10] Liu, K., Kaleas, D., \& Ruuspakka, R. Prototyping interaction with everyday artifacts: training and recognizing $3 \mathrm{D}$ objects via Kinects. International Conference on Tangible, Embedded and Embodied Interaction. ACM, 2012, pp. 241-244. https://doi.org/10.1145/21 $\underline{48131.2148182}$

\section{Authors}

Feng Sheng is a lecturer in the Qufu Normal University, Qufu 273165, China (3352165615@qq.com).

Shaozeng Sheng is a lecturer in the Qufu Normal University, Qufu 273165, China (3352165615@qq.com).

Article submitted 17 March 2018. Final acceptance 23 April 2018. Final version published as submitted by the authors. 